\title{
Jurnal

\section{DETERMINAN INSIDEN HIPOGLIKEMIA PADA PASIEN DIABETES MELLITUS TIPE 2: STUDI LITERATUR}

\section{Determinants of Incident Hypoglycemia in Patients with Diabetes type 2: Literature Review}

\section{Zaqqi Ubaidillah, Desy Ayu Permata Sari, Erma Wahyu Mashfufa}

Fakultas Ilmu Kesehatan Universitas Muhammadiyah Malang, Indonesia

\section{Riwayat artikel}

Diajukan: 7 Agustus 2021

Diterima: 16 September

2021

\section{Penulis Korespondensi:}

- Zaqqi Ubaidillah

- Universitas

Muhammadiyah

Malang

e-mail:

ubaidillah@umm.ac.id

\section{Kata Kunci:}

Hypoglycemia, Factors, Type 2 Diabetes Mellitus

\section{Abstrak}

Pendahuluan : Hipoglikemia terjadi ketika kadar gula darah $<70 \mathrm{mg} / \mathrm{dl}$ disertai adanya gelaja klinis. Ini merupakan komplikasi akut diabetes melitus. (Riskesdes 2014), Diperoleh data bahwa diabetes tipe 2 merupakan $90 \%$ dari seluruh diabetes. Pada tahun 2017, diabetes militus di Indonesia meningkat 1,4\%. Sebanyak 10\%-30\% mengalami hipoglikemi dengan angka kematian 3\%-4\% (Diabetes Militus tipe 1). Sedangkan 1,2\% kejadian pada diabetes melitus tipe 2 . Oleh karena itu, tujuan penelitian untuk mengidentifikasi faktor yang mempengaruhi kejadian hipoglikemia pada pasien diabetes melitus tipe 2. Agar selanjutnya dapat membantu meningkatkan penanganan hipoglikemia secara optimal. Metode:Studi literatur dari 16 jurnal internasional dengan kriteria inklusi usia 45-90 tahun, jurnal full text, dan rentang tahun 2016-2020, hipoglikemia, diabetes tipe 2. Data berdasarkan data artikel yang diterbitkan oleh NCBI dan Google Scholar. Data dianalisis dengan analisis deskriptif . Hasil: Usia, Jenis Kelamin, Penggunaan Sulfonilurea, Pengetahuan, Indeks Masa Tubuh, Fungsi Ginjal, Riwayat Hipoglikemia, Olahraga /Aktifitas Fisik, Pola Makan dan Durasi Diabetes adalah faktor faktor yang peneliti temukan.. Kesimpulan:Data diperoleh mengenai beberapa faktor hipoglikemia. Faktor tersebut meliputi usia, jenis kelamin, pengunaan sulfonilurea, pengetahuan hipoglikemia, indeks masa tubuh, penurunan fungsi ginjal, riwayat hipoglikemia, olahrga /aktifitas fisik, pola makan (menunda atau melewatkan makan), dan durasi diabetes .

Abstract

Background: Hypoglycemia occurs when the blood sugar level is $<70 \mathrm{mg} / \mathrm{dl}$ in the presence of clinical symptoms. This is an acute complication of diabetes mellitus. (Riskesdes 2014), obtained the data that diabetes type 2 is $90 \%$ of all diabetes. In 2017, diabetes mellitus in Indonesia increased by 1.4\%. As many as $10 \%-30 \%$ had hypoglycemia with a mortality rate of $3 \%-4 \%$ (Diabetes mellitus type 1). Meanwhile, $1.2 \%$ incidence in type 2 diabetes mellitus. Therefore, the aim is to investigate the factors that influence the incidence of hypoglycemia in type 2 diabetes mellitus patients. In order to further help improve the optimal management of hypoglycemia. Method: Literature study from 16 international journals with the inclusion criteria of ages 45-90 years, full text journals, and ranges for the years 2016-2020, hypoglycemia, type 2 diabetes. Data based on data published article by NCBI and Google Scholar. Data were analyzed with descriptive analysis. Results: Age, Gender, Use of Sulfonylurea, Knowledge, Body Mass Index, Kidney Function, History of Hypoglycemia, Exercise / Physical Activity, Diet and Diabetes Duration were factors that the researchers found. Conclusion:Data obtained on several factors hypoglycemia. These factors include age, gender, use of sulfonylureas, knowledge of hypoglycemia, body mass index, decreased kidney function, history of hypoglycemia, exercise / physical activity, diet (delaying or skipping meals), and duration of diabetes 


\section{PENDAHULUAN}

tahun 2012 terdapat 108.000 .000

kasus diabetes melitus. Sedangkan pada tahun 2017 kasus diabetes melitus meningkat sebanyak 425.000.000 kasus di dunia (IDF, 2018). Di Indonesia pada tahun 2012 sebanyak 102.399 kasus diabetes melitus. Di tahun 2017 jumlah kasus diabetes yang dilaporkan sebanyak 10.300.000 kasus (Kemenkes, 2018). Pasien diabetes melitus di Indonesia yang mengalami hipoglikemia tercatat sebanyak 10\%-30\% pasien per tahun dengan angka kematian nya $3 \%$ - $4 \%$ pada pasien diabetes melitus tipe 1(Goldman L, 2012). Sedangkan pada diabetes tipe 2 angka kejadiannya $1,2 \%$ pasien per tahun. Hipoglikemia terjadi sebanyak $30 \%$ per tahun pada pasien diabetes melitus yang mengonsumsi obat hipoglikemia oral seperti sulfonilurea (Self WH, 2013).

Hipoglikemia adalah komplikasi akut dari diabetes melitus tipe 2 . Hipoglikemia terjadi akibat dari kadar gula darag dibawah normal $<70 \mathrm{mg} / \mathrm{dl}$. Gejala hipoglikemia akan terasa jika seseorang mengalami gula darah $<70 \mathrm{mg} / \mathrm{dl}$. Glukosa diperoleh dari makanan yang kita cerna dan serap. Molekul glukosa memasuki aliran darah untuk didistribusikan ke semua sel yang ada di jaringan tubuh. Tetapi sebagian sel-sel jaringan tubuh tidak dapat menyerap glukosa tanpa peran hormon insulin yang diproduksi oleh selbeta pankreas. Sehingga hipoglikemia merupakan salah satu faktor penghambat untuk mencapai pengobatan yang optimal pada pasien diabetes melitus (Setyawati, 2016).

Hipoglikemia membutuhkan penanganan dengan cepat dan tepat sehingga tidak berdampak pada kerusakan organ utama manusia terutama otak. Penurunan kadar glukosa darah dibawah normal akan berdampak secara akut pada fungsi otak karena otak sangan tergantung pada glukosa dan otak tidak dapat menyimpan cadangan glukosa untuk proses metabolisme. Sel otak akan mengalami iskemia apabila tidak mendapatkan oksigen dan glukosa 4-6 menit, serta dapat menimbulkan kerusakan otak yang bersifat irreversible jika lebih dari 10 menit. Selain itu hipoglikemia dapat mengancam kehidupan, secara psikologis hipoglikemia juga memberi dampak negatif bagi pasien dan pengelolaan diabetes melitusnya (Sutawardana, 2016).

Angka kejadian hipoglikemia terus mengalami peningkatan mengikuti peningkatan kejadian diabetes melitus tipe 2 di Indonesia (PERKENI, 2015). Upaya pencegahan harus dilakukan oleh perawat untuk mencegah terjadinya perburukan pada klien diabetes. oleh sebab itu, perlu adanya kajian faktor-faktor apa saja yang meningkatkan insiden terjadinya hipoglikemia berdasarkan berbasis bukti atau evidence of nursing.

\section{METODE}

Penelitian ini menggunakan metode Literature Review. Adapun mesin pencarian yang digunakan menggunakan NCBI dan google scholar, menggunakan kata kunci "type 2 diabetes, hypoglycemia, risk factor, adults". Kriteria jurnal yang dicari sebagai berikut: a. Jurnal international yang membahas topik; b. Tahun terbit jurnal dalam rentang waktu 2016-2020; c. Jurnal dalam bentuk full text (dapat diakses secara penuh); d. Jurnal yang terdapat faktor-faktor hipoglikemia; e. Responden yang mengalami diabetes melitus tipe 2 . f. Responden yang berusia 45-90 tahun. Analisa data yang digunakan menggunakan tematik analisis.

\section{HASIL DAN PEMBAHASAN HASIL}

Jurnal yang didapatkan yang mempresentasikan tujuan penelitian terdapat 16 jurnal. Berdasarkan hasil tematik analisis didapatkan bahwa faktorfaktor yang mempengaruhi terjadinya hipoglikemia pada klien diabetes tipe 2 antara lain,

1) Faktor demografi

2) Penggunaan sulfonylurea 
3) Tingkat pengetahuan

4) Indeks masa tubuh

5) Penurunan fungsi ginjal

6) Riwayat hipoglikemia sebelumnya

7) Aktivitas fisik

8) Pola makan

9) Durasi diabetes

\section{PEMBAHASAN}

\section{a. Faktor Demografi}

Faktor demografi yang dapat berpengaruh antara lain, usia dan jenis kelamin. Usia lanjut dianggap lebih rentan terhadap hipoglikemia karena perubahan terkait penuaan dalam pembersihan obat, tanggapan kontra-regulasi, dan polifarmasi yang sangat lazim. Dalam peningkatan resiko $20 \%$ hingga $95 \%$ untuk pasien berusia $>75$ tahun. (Augello and Ceriello, 2016). Sejalan dengan hasil penelitian lain, menyatakan bahwa pasien diabetes yang berusia lebih muda memiliki kualitas hidup yang lebih baik dibandingkan dengan pasien usia lanjut ( Imayama, Plotnikof, Courneya, \& Johnson, 2010). Besradasarkan asumsi peneliti, seiring bertambahnya usia seseorang mengalami perubahan secara fisiologis, psikologis maupun intelektual. Penambahan usia pada lansia akan berdampak pada perubahan anatomis, dan fisiologis yang berdampak pada kerentanan suatu penyakit. Sehingga pasien lanjut usia cenderung lebih berisiko hipoglikemia.

Jenis kelamin perempuan lebih berisiko hipoglikemia daripada laki-laki. Perempuan memiliki perlindungan terhadap diabetes sebelum menopause daripada pria, karena pada perempuan menopause akan terjadi penurunan jumlah estrogen dan progesteron, seperti yang diketahui bahwa hormon tersebut dibentuk dari steroid yang diambil dari jaringan adipose. Penurunan jumlah hormon estrogen dan progesteron akan meningkatkan timbunan lemak dan perubahan profil lipid darah dapat menurunkan sensitifitas terhadap kerja insulin pada otot dan hati (Kautzky-willer $e t$ $a l .$, 2012). Sejalan dengan penelitian lain bahwa jenis kelamin dengan kualitas hidup, dimana jenis kelamin laki-laki mempunyai kualitas hidup yang lebih baik daripada perempuan ( Chyun, Melkus, Katten, \& Price, 2006). Berdasarkan asumsi peneliti, jenis kelamin perempuan memiliki tingkat ketakutan hipoglikemia lebih tinggi daripada laki-laki.

\section{b. Penggunaan Sulfonilurea}

Sulfonilurea diketahui meningkatkan resiko hipoglikemia dibandingkan obat oral lainnya. Karena banyak pasien yang mengalami hipoglikemia menggunkan obat sulfonilurea dibandingkan dengan pasien tanpa hipoglikemia (Augello and Ceriello, 2016). Hipoglikemia terjadi sebanyak $30 \%$ per tahun pada pasien diabetes melitus yang mengonsumsi obat hipoglikemia oral terutama adalah jenis sulfonilurea (Self WH, 2013) Risiko terjadinya hipoglikemia pada orang diabetes yang mengkonsumsi sulfonilurea saja lebih tinggi secara signifikan dibandingkan dengan pengguna metformin (rasio hazard yang disesuaikan 2,50, interval kepercayaan 95\% 2,23 hingga 2,82). Disamping itu, resiko terjadinya hipoglikemia lebih tinggi pada pengguna sulfonilurea pada pasien diabetes dengan perkiraan laju filtrasi glomerulus kurang dari $30 \mathrm{~mL} / \mathrm{menit} / 1,73 \mathrm{~m} 2 \quad(4,96,3,76$ hingga 6,55). Dan juga, Risiko hipoglikemia juga secara signifikan lebih tinggi pada pasien pengguna sulfonylurea dengan dosis tinggi $(3,12,2,68$ hingga 3,62$)$ dan pada pengguna glibenklamid $(7,48,4,89$ hingga 11,44). Penelitian tersebut juga menyimpulkan bahwa Gliclazide, merupakan jenis sulfonilurea pilihan pertama, menunjukkan risiko hipoglikemia yang serupa dibandingkan dengan sulfonilurea lainnya (van Dalem et al., 2016). Sebagai penyulit akut pada pasien diabetes melitus tipe 2, hipoglikemia paling sering disebabkan oleh penggunaan insulin dan sulfonilurea (PERKENI, 2015). Sejalan dengan penelitian lain yang mengatakan, 
bahwa sulfonilurea 4,5 kali lebih tinggi berisiko hipoglikemia.

\section{c. Pengetahuan}

Pengetahuan berisiko hipoglikemia pada diabetes tipe 2. Orang dengan pengetahuan rendah memiliki resiko $75 \%$ pasien memiliki episode hipoglikemik sedang atau berat (Besen, Sürücü and Ko, 2016). Sejalan dengan penelitian lain, menyatakan bahwa pengetahuan tentang hipoglikemia menurun seiring dengan bertambahnya usia ( Shriraam, Mahadevan, Jagadeesh, \& Kurup, 2015).

Sesuai dengan penelitian lain, bahwa kebanyakan pasien yang kurang pengetahuan untuk mengenali gejala hipoglikemia dapat menyebabkan pengobatan tertunda yang bahkan menyebabkan kematian. Pasien tidak menyadari hipoglikemia karena rendahnya pengetahuan untuk mengenali gejala-gejala tersebut dan bisa berakibat hipoglikemia yang berkepanjangan yang berdampak pada cedera otak, kejang karena otak bergantung pada glukosa darah sebagai energi yang diperlukan untuk aktivitasnya dan tidak dapat bertahan lebih dari 6 menit (THENMOZHI P, 2018). Berdasarkan asumsi peneliti, pendidikan terkait hipoglikemia perlu diberikan agar pasien dapat memahami penyakit yang dialaminya. Sehingga pasien memiliki pengetahuan untuk mencegah agar tidak terjadi hipoglikemia ringan.

\section{d. Indeks Masa Tubuh}

Risiko hipoglikemia tertinggi ditemukan pada pasien dalam kategori BMI rendah $\left(<18,5 \mathrm{~kg} / \mathrm{m}^{2}\right)$, dibandingkan dengan rentang referensi (BMI 18,5- $<23,0$ $\left.\mathrm{kg} \mathrm{/} \mathrm{m}^{2}\right)$. BMI yang lebih rendah mencerminkan efek dari malnutrisi, yang telah dikaitkan dengan risiko hipoglikemia yang lebih tinggi. Pada pasien yang memiliki berat badan rendah, kapasitas sekresi insulin mengalami penurunan. risiko hipoglikemia berat sedikit meningkat pada kelompok dengan kelas obesitas II (BMI, $\geq 30 \mathrm{~kg} / \mathrm{m} 2$ ) dibandingkan dengan dengan kelas obesitas I (BMI, 25-29 kg / m 2 ) (Yun, Park, \& Han, 2019).

Sejalan dengan penelitian lain, bahwa BMI yang lebih rendah berisiko hipoglikemia (Misra-Heber, Pantalone, Xinge Ji, \& Milinovich, 2018). Tidak sejalan dengan penelitian (Festa, Seaquist, Duan, Hadjiyianni, \& Fu, 2016), menyatakan bahwa BMI yang lebih tinggi berisiko hipoglikemia. Berdasarkan asumsi peneliti, BMI yang lebih rendah berisiko hipoglikemia karena pasien yang memiliki berat badan rendah memiliki asupan nutrisi yang kurang sehingga pasien mengalami kadar gula darah rendah.

\section{e. Penurunan Fungsi Ginjal}

Penurunan fungsi ginjal adalah pencetus terjadinya hipoglikemia. Secara normal baik hati dan ginjal memainkan peran yang sama pentingnya untuk kontra regulasi hipoglikemia melalui glukoneogenesis. Pasien memiliki kondisi ginjal kronis memiliki massa ginjal yang berkurang, dan dengan demikian menurunkan kapasitas pelepasan glukosa ginjal. Penurunan fungsi ginjal menyebabkan berkurangnya pembersihan insulin pada pasien yang diberikan dosis insulin kerja panjang dengan demikian dapat menyebabkan pasien memiliki risiko hipoglikemia yang lebih besar ( $\mathrm{Pv}$ et al., 2016).

Sejalan dengan penelitian lain bahwa penyakit ginjal kronis merupakan faktor risiko yang signifikan untuk perkembangan hipoglikemia dengan atau tanpa adanya diabetes, tetapi risiko terbesar pada pasien penyakit ginjal kronis dan diabetes. Resiko untuk kematian, baik yang dialami di dalam atau di luar rumah sakit (Moen, Zhan, Hsu, \& Walker, 2009). Berdasarkan asumsi peneliti, penurunan fungsi ginjal berisiko hipoglikemia. Penurunan fungsi ginjal dapat menyebabkan penurunan pelepasan kapasitas glukosa ginjal.

\section{f. Riwayat hipoglikemia}


Pasien diabetes yang pernah mengalami hipoglikemia ringan yang merupakan efek samping memulai insulin, sehingga dapat menyebabkan terjadi nya hipoglikemia berat. Tingkat hipoglikemia ringan adalah satu-satunya faktor risiko yang terkait dengan tingkat kejadian peristiwa hipoglikemik berat. Hipoglikemia ringan dapat membantu mengidentifikasi tindakan pencegahan untuk kejadian hipoglikemik, khususnya untuk hipoglikemia berat (Festa et al., 2016). Sejalan dengan penelitian lain, bahwa riwayat hipoglikemia berhubungan signifikan dengan risiko hipoglikemia yang lebih berat (Misra-Heber, Pantalone, Xinge Ji, \& Milinovich, 2018). Berdasarkan asumsi peneliti, bahwa hipoglikemia ringan adalah sinyal pertama untuk kejadian hipoglikemia berat. Sehingga pasien yang pernah mengalami hipoglikemia akan memunculkan hipoglikemia yang lebih parah tetapi tidak merasakan gejala apa-apa.

\section{g. Olahraga/ latihan fisik}

Aktivitas fisik merupakan landasan untuk pengolaan pencegahan diabetes yang efektif. Olahraga meningkatkan penurunan dan pemeliharaan berat badan, insulin hati dan perifer sensitivitas, pengambilan dan pemanfaatan glukosa, dan kesehatan jantung. Pada orang dengan pradiabetes, risiko terkena diabetes dapat diturunkan hingga 58\% dengan diet gabungan, latihan dan modifikasi perilaku. Olahraga dapat meningkatkan risikonya hipoglikemia pada individu dengan diabetes. Tanpa pengurangan insulin yang cukup dan / atau suplementasi karbohidrat, hipoglikemia terkait olahraga dapat terjadi pada pasien diabetes beberapa jam setelah satu kali latihan. Aktifitas fisik yang dianjurkan latihan minimal 150 menit per minggu. Pasien harus berusaha untuk mempertahankan jadwal olahraga teratur, menghindari latihan aerobik tidak lebih dari dua hari berturut-turut. Asupan karbohidrat tambahan harus dikonsumsi jika kadar glukosa darah kurang dari 100 mg / dl (5,6 mmol / 1) sebelum memulai latihan. Pasien sebaiknya tidak berolahraga selama periode hipoglikemia. Selain itu, olahraga harus dihindari selama 24 jam setelah episode hipoglikemia, sehingga meningkatkan risiko berulang hipoglikemia (Younk, Mikeladze, Tate, \& Davis, 2011).

Sejalan dengan penelitian lain mentakan bahwa olahraga sangat baik untuk membantu mengurangi kadar gula darah, hilangkan berat badan, membakar kalori, dan memiliki lebih banyak energi. Olahraga 15 setelah makan membuat penurunan yang signifikan pada profil glukosa. Aktifitas jalan cepat lebih mudah dilakukan, termasuk aktivitas aerobik. Berjalan dikecepatan 4,8 $\mathrm{km} /$ jam, dengan intensitas latihan 3,3 MET. Olah raga pasca makan lebih efektif dibandingkan olah raga rutin satu kali sehari untuk pengendalian glikemik pada diabetes melitus tipe 2 (Pahra et al., 2017). Berdasarkan asumsi peneliti, aktifitas fisik/ olahraga yang berlebihan dapat berisiko mengalami hipoglikemia. Sehingga pasien dianjurkan makan sebelum melakukan aktifitas fisik, agar tidak menyebabkan penurunan kadar gula darah yang lebih parah lagi.

\section{h. Pola Makan (menunda atau melewatkan makan)}

Klien dengan pengobatan insulin atau obat oral untuk diabetes, seringkali makan lebih lambat dari yang direncanakan atau melewatkan makan, yang berakibat hipoglikemia. Pasien dengan diabetes melitus dianjurkan untuk melakukan pola makan yang teratur untuk menghindari terjadinya hipoglikemia (Stoltz, 2019).

Sejalan dengan penelitian lain, menyatakan bahwa episode hipoglikemia akibat dari menunda asupan makan dapat berisiko hipoglikemia (Samya et al., 2019). Penelitian ini juga di dukung oleh hasil penelitian menunjukkan hasil bahwa puasa 7x lipat lebih berisiko hipoglikemia, terutama yg menggunakan insulin, dan mereka yang aktif secara fisik Alqahtani, (Mishriky, \& Aljadhey, 2016). Berdasarkan 
asumsi peneliti bahwa pola makan yang tertunda atau terlewat akan berisiko hipoglikemia. Jika pasien tersebut mengonsumsi insulin atau obat hipoglikemik oral tetapi pasien melewatkan atau menunda makan.

i. Durasi Diabetes

Semakin lama durasi pasien menderita diabetes maka dapat meningkatkan kejadian hipoglikemia. Karena pasien merasa penyakit tersebut telah bertahun-tahun tidak sembuh, sehingga pasien berhenti melakukan pengobatan, mengotrol kadar gula darah, tidak patuh terhadap diet dan minum obat. Durasi lama nya menderita diabetes mengakibatkan pasien cenderung mengalami hipoglikemia berulang selama perawatan di rumah sakit. Hal ini terkait dengan penurunan fungsi mekanisme counterregulatory, tingkat albumin yang rendah termasuk peradangan, infeksi dan trauma (Ernawati, 2010).

Sejalan dengan penelitian lain menyatakan bahwa, ada hubungan yang signifikan antara durasi penyakit dengan risiko hipoglikemia (Torimoto, Okada, \& Hajime, 2018). Penelitian ini juga didukung oleh hasil penelitian menunjukkan hasil bahwa durasi diabetes ( $\geq 20$ tahun) memiliki efek signifikan pada hipoglikemia (Fukuda, Doi, Sugawara, \& Mochizuki, 2019). Dan penelitian menurut (Dissanayake, 2018) menyatakan bahwa durasi diabetes meningkat dengan meningkatnya episode hipoglikemia. Berdasarkan asumsi peneliti bahwa durasi diabetes yang lebih lama dapat meningkatkan risiko hipoglikemia. Karena pasien menganggap penyakitnya tak kunjung sembuh sehingga pasien tidak memperhatikan kepatuhan terhadap diet, obat dan aktifitas fisiknya.

\section{KESIMPULAN}

Setelah hasil penelitian studi literatur yang menggunakan analisa jurnal dilakukan terhadap 16 jurnal International, maka dapat ditarik suatu kesimpulan bahwa dalam studi literatur ini usia, jenis kelamin, penggunaan sulfonilurea, pengetahuan, indeks masa tubuh, penurunan fungsi ginjal, riwayat hipoglikemia, olahraga atau aktifitas fisik, pola makan (menunda atau melewatkan makan), durasi diabetes, merupakan faktorfaktor yang mempengaruhi kejadian hipoglikemia pada pasien diabetes melitus tipe 2

\section{DAFTAR PUSTAKA}

Augello, G. G. and Ceriello, G. G. A. (2016) 'Risk factors for hypoglycemia in patients with type 2 diabetes, hospitalized in internal medicine wards: Findings from the FADOIDIAMOND study'. doi: 10.1016/j.diabres.2016.01.020.

Besen, D. B., Sürücü, H. A. and Ko, C. (2016) 'Self-reported frequency, severity of , and awareness of hypoglycemia in type 2 diabetes patients in Turkey', pp. 1-14. doi: 10.7717/peerj. 2700.

van Dalem, J. et al. (2016) 'Risk of hypoglycaemia in users of sulphonylureas compared with metformin in relation to renal function and sulphonylurea metabolite group: population based cohort study', $B M J$, 354, p. i3625. doi: 10.1136/bmj.i3625.

Ernawati (2010) 'Kemampuan Melakukan Penatalaksanaan Hipoglikemia Berdasarkan Karakteristik dan Pengetahuan Pasien Diabetes Melitus'.

Festa, A. et al. (2016) 'Association between mild and severe hypoglycemia in people with type 2 diabetes initiating insulin'. doi: 10.1016/j.jdiacomp.2016.12.014.

Goldman L, S. A. (2012) 'Hypoglycemia 
(disorder)', Elsevier Inc. Diakses 01 September 2014. Dari http//:www.clinicalkey.com/\#!topic/h ypoglycemia.

IDF (2018) International Diabetes Federation.

Kautzky-willer, S. et al. (2012) 'Women are more prone to hypoglycaemia than men', (June), pp. 1-2. doi: 10.1038/oby.2011.384.

Kemenkes (2018) 'Badan Penelitian dan Pengembangan Kesehatan Kementerian Kesehatan RI'.

Pahra, D. et al. (2017) 'Impact of post - meal and one - time daily exercise in patient with type 2 diabetes mellitus: a randomized crossover study', Diabetology \& Metabolic Syndrome. BioMed Central, pp. 5-11. doi: 10.1186/s13098-017-0263-8.

PERKENI (2015) Konsensus Pengelolaan Dan Pencegahan Diabetes Melitus Tipe 2 Di Indonesia 2015, PERKENI. Available at: https://pbperkeni.or.id/wpcontent/uploads/2019/01/4.-

Konsensus-Pengelolaan-danPencegahan-Diabetes-melitus-tipe-2di-Indonesia-PERKENI-2015.pdf.

$\mathrm{Pv}, \mathrm{V}$. et al. (2016) 'Incidence and risk factors of hypoglycemia among Type 2 diabetic patients in a South Indian hospital', Diabetes \& Metabolic Syndrome: Clinical Research \& Reviews. Diabetes India, pp. 2-5. doi: 10.1016/j.dsx.2016.01.014.

Samya, V. et al. (2019) 'Prevalence of Hypoglycemia Among Patients With Type 2 Diabetes Mellitus in a Rural Health Center in South India'. doi: $10.1177 / 2150132719880638$.

Self WH, M. C. (2013) 'Hypoglycemia', In (Adam James G) Emergency Medicine Clinical Essential Second Ed. Elsevier Inc : 1379-1390.

Setyawati, T. (2016) 'Complication of Hypoglycemia in Patients with Type 2 Diabetes Mellitus in RSUD Undata
Palu in 2016', Departement of Biochemistry, Faculty of Medicine, Tadulako University, Vol 1, No.

Stoltz, B. C. (2019) 'Causes and Risk Factors of Hypoglycemia', pp. 1-5.

Sutawardana,et al (2016) '( phenomenology study the experience of persons with diabetes melli- Program Magister Ilmu Keperawatan Kekhususan Keperawatan Medikal Bedah', 1(1).

Septikasari, M. (2018) Status Gizi Anak dan Faktor yang Mempengaruhi. Yogyakarta: UNY Press.

Soetjiningsih and Ranuh, I. N. G. (2014) Tumbuh Kembang Anak. Jakarta: EGC.

Supariasa, I. D. N., Fajar, I. and Bakri, I. (2001) Penilaian Status Gizi. Jakarta: EGC. 